\title{
Parents' preferences for participation in decisions made regarding their child's anaesthetic care
}

\author{
ALAN R. TAIT PhD, TERRI VOEPEL-LEWIS BSN, MS, \\ HAMISH M. MUNRO MD, FRCA AND SHOBHA MALVIYA MD \\ Department of Anesthesiology, The University of Michigan Medical Center, Ann Arbor, MI, \\ USA
}

\begin{abstract}
Summary
Background: The traditional paternalistic approach to medical decision-making is moving towards a climate of greater patient and/or surrogate involvement. Despite this, there is considerable debate regarding patient preferences for participation in medical decisionmaking and its effect on patient satisfaction and outcome. This study was designed to examine parents' preferences for participation in decisions regarding their child's anaesthetic care and to determine if active participation is associated with greater parental satisfaction. Methods: Three hundred and eight parents of children scheduled to undergo elective surgical procedures were asked to complete a questionnaire detailing information regarding their preferences for participation in decisions made regarding their child's anaesthetic care. Parents were classified as being passive, shared, or active decision makers.

Results: Overall, parents evidenced a preference for shared decisionmaking with the anaesthetist. Parents preferred to be passive with respect to intraoperative pain management but active with respect to their presence when their child wakes up. There were no differences between active, shared and passive decision-makers with respect to their satisfaction with anaesthetic care and their participation in decision-making. However, $32.1 \%$ of parents stated that they would have preferred more involvement in decision-making. These parents were significantly less satisfied with their child's care than those who felt that their participation had been adequate.

Conclusions: This study highlights specific areas in which parents would prefer a more active role in decision-making and, as such, may serve to focus anaesthetists' efforts to educate parents with respect to the various options available for their child's care.
\end{abstract}

Keywords: preferences; satisfaction; anaesthetic care

Correspondence to: Alan R. Tait, Department of Anesthesiology, University of Michigan Medical Center, 1500 East Medical Center Drive, Ann Arbor, MI 48109, USA (e-mail: atait@umich.edu). 


\section{Introduction}

Traditionally, decisions made regarding patient care and treatment have followed a paternalistic approach in which the axiom 'doctor knows best' was considered the norm. However, since the 1980s, this passive approach appears to be slowly moving towards an environment of greater patient autonomy (1). Despite this, it is unclear as to what extent patients want to be involved in making decisions about their care. While some studies suggest that allowing patients to participate in medical decision-making increases patient satisfaction, compliance with treatment regimens, and outcome $(2,3)$, others question patients' desire for active involvement (4-6).

Patient satisfaction has become an important measure of the quality of health care. Although there are several patient satisfaction surveys addressing anaesthetic care, none of these surveys take into account patient preferences (7-9). Furthermore, none address parents' preferences for the anaesthetic care of their child. This study therefore was designed to determine the extent to which parents wish to participate in decisions regarding their child's care and to examine whether active participation is associated with improved parental satisfaction. The hypothesis to be tested is that active parental participation in decisions regarding their child's anaesthetic care improves satisfaction.

\section{Methods}

This study was approved by our institutional review board. The study population included consecutive parents/guardians of children scheduled to undergo a surgical procedure at a large tertiary care children's hospital. Prior to surgery, as soon as possible after arrival in the preoperative waiting area, parents/guardians were given a questionnaire designed to elicit information regarding their preferences for participation in decisions regarding their child's anaesthetic care. In addition, the questionnaire examined their relative concerns regarding various aspects of their child's perioperative care. Items for the questionnaire were generated following informal discussions with parents, anaesthetists and nursing personnel. The questionnaire was completed in the outpatient waiting room and returned to a research assistant prior to their child's discharge from the hospital.

Responses to items addressing parental preferences for participation in decisions regarding specific aspects of their child's care were determined by offering the five options below. These options were based on previously published work by Stiggelbout et al. (6).

(i) 'I would prefer that the anaesthetist make all the decisions regarding ... insert specific aspect of care e.g. my child's overall anaesthetic care, type of anaesthetic, my being present at induction, my child's need for premedication, etc.'

(ii) 'I would prefer that the anaesthetist make all the final decisions regarding ... after carefully considering my opinions.'

(iii) 'I would prefer that the anaesthetist and I make equal decisions regarding ...'

(iv) 'I would prefer that I make all the final decisions regarding ... after carefully considering the anaesthetist's opinions.'

(v) 'I would prefer that I alone make all the final decisions regarding ...'

Items that contained terms that may have been unfamiliar to parents were explained. For example, type of anaesthetic was explained as the child either having a shot or having to breathe an anaesthetic gas. Parents who selected option 1 or 2 for decisions made about the overall anaesthetic care of their child were classified as passive decision-makers. Those selecting option 3 were classified as shared decisionmakers, and those responding to option 4 or 5 , active decision-makers.

Questions examining parents' concerns regarding aspects of their child's care were measured using a 5-point Likert scale of 'not concerned', 'slightly concerned', 'moderately concerned', 'very concerned' and 'extremely concerned.' Parental anxiety was measured using a visual analogue scale (VAS): $(0=$ no anxiety, $10=$ extremely anxious). Although there are more comprehensive and valid measures of anxiety, the VAS represents a simple means to obtain a global assessment of parental anxiety (10).

One day following their child's surgery, parents were contacted by telephone to determine if they were satisfied with their degree of participation in 
decisions made regarding their child's anaesthetic care or if they would have liked more involvement. Additionally, parents were asked to rate their satisfaction with various aspects of their child's anaesthetic care, their interactions with staff, and the hospital environment. Statements of satisfaction were measured using a 4-point Likert scale of 'strongly agree', 'agree', 'disagree' and 'strongly disagree.' Furthermore, 10-point analogue scales were used to measure parents' satisfaction with their child's overall anaesthetic and surgical care and satisfaction with their participation in decisionmaking $(0=$ not at all satisfied, $10=$ extremely satisfied). Telephone interviews with parents followed a set script to ensure consistency. Postoperative (hospital and home) pain scores and the incidence of postoperative nausea and vomiting (PONV) were recorded prospectively.

Nonparametric data were analysed using chisquare, Fisher's exact tests, and Mann-Whitney $U$ tests. Parametric data were analysed using $t$-tests and ANOVA. Correlations were analysed using Pearson's correlation coefficient or Spearman's rho. Internal consistency measures of reliability of items in the questionnaire were obtained by calculation of Coefficient (Cronbach) $\alpha$. Coefficient $\alpha$ values of $\geq 0.7$ were considered to represent satisfactory reliability. Data are expressed as mean \pm SD. $P<0.05$ was considered statistically significant.

\section{Results}

A total of 331 parents/guardians were approached to participate in the study. Nine parents declined to participate and 14 did not complete the survey.
Completed questionnaires were obtained for 308 parents indicating a response rate of $93.1 \%$. The questionnaire was shown to be highly reliable. Internal consistency measures of reliability of items measuring preferences (11 items), concerns (11 items), and satisfaction (8 items) yielded coefficient $\alpha$ values of $0.91,0.88$ and 0.90 , respectively.

Table 1 describes the demographics of the study sample by overall decision-making preference. There were no differences in overall decisionmaking by child's age, child's previous surgery and parents' level of education. However, AfricanAmerican parents were significantly $(P<0.025)$ more likely to be passive decision-makers compared to Caucasians.

Figures 1-4 describe parental preferences for decisions made regarding overall anaesthetic care, intraoperative pain control, parental presence at induction and presence on awakening. In general, parents evidenced a preference for equal shared decision-making with the anaesthetist. Preferences for equal shared decision-making were most evident with respect to: choice of postoperative pain control (mode $=50.0 \%$ of respondents); type and need for premedication $(48.7 \%$ and $47.7 \%$, respectively); home readiness $(50.0 \%)$; and, decisions to admit to the hospital $(48.4 \%)$. Respondents were evenly split between passive and shared decision-making with respect to choice of anaesthetic technique, i.e. i.v. versus inhalation $(41.9 \%$ passive, $43.5 \%$ shared), and choice of PONV management/treatment (45.5\% passive, $43.5 \%$ shared). Only five parents (1.6\%) felt that the anaesthetist alone should make the decision regarding parental presence at induction and 56 $(18.2 \%)$ felt that they alone should make the deci-
Table 1

Patient demographics

\begin{tabular}{lccc}
\hline & $\begin{array}{l}\text { Passive } \\
(\mathrm{n}=143)\end{array}$ & $\begin{array}{l}\text { Shared } \\
(\mathrm{n}=131)\end{array}$ & $\begin{array}{l}\text { Active } \\
(\mathrm{n}=33)\end{array}$ \\
\hline $\begin{array}{l}\text { Child's age (mean } \pm \mathrm{SD} \text {, years) } \\
\text { Previous surgery, } \mathrm{n}(\%)\end{array}$ & $6.5 \pm 5.6$ & $7.6 \pm 6.6$ & $6.7 \pm 4.5$ \\
$\begin{array}{l}\text { Racial/ethnic background, } n(\%) \\
\text { Caucasian }\end{array}$ & $80(46.0)$ & $79(45.4)$ & $15(8.6)$ \\
$\quad$ African-American & $123(46.9)$ & $108(41.2)$ & $31(11.8)$ \\
$\quad$ Other & $9(81.8)^{*}$ & $1(9.1)$ & $1(9.1)$ \\
Parental education, $n(\%)$ & $9(39.1)$ & $14(60.9)$ & 0.0 \\
$\quad$ Grade school & $3(75)$ & $1(25)$ & 0.0 \\
High school graduate & $28(38.9)$ & $38(52.8)$ & $6(8.3)$ \\
College graduate & $36(45.0)$ & $36(45.0)$ & $8(10.0)$ \\
Graduate school & $28(57.1)$ & $13(26.5)$ & $8(16.3)$ \\
\hline
\end{tabular}

${ }^{*} P<0.05$ versus Caucasians. 


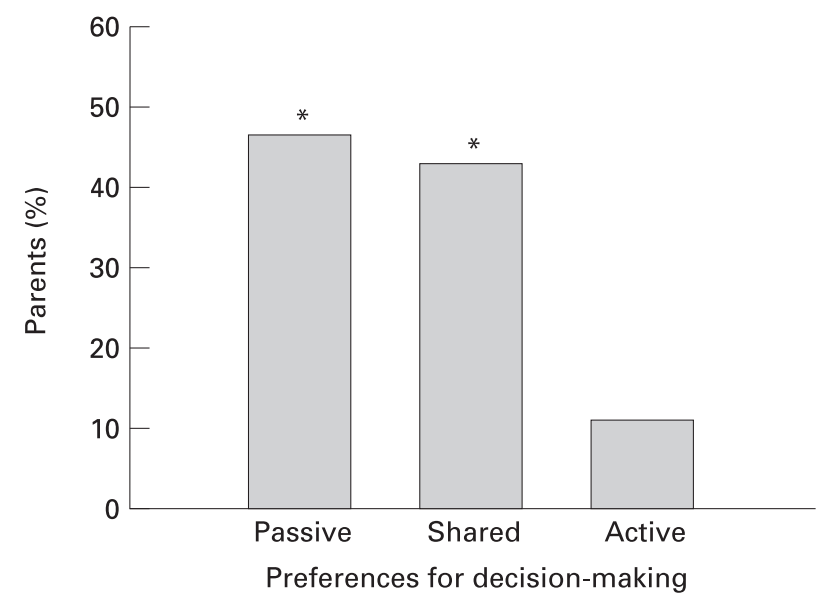

Figure 1

Parents' decision-making preferences with respect to their child's overall anaesthetic care. ${ }^{*} P<0.05$ versus active decision-makers.

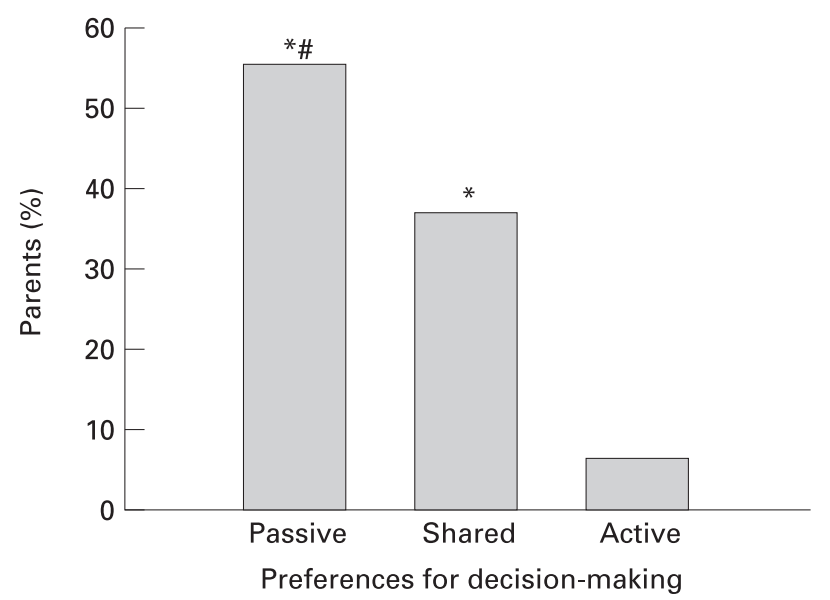

Figure 2

Parents' decision-making preferences with respect to intraoperative pain control. ${ }^{*} P<0.05$ versus active decision-makers, $\# P<0.05$ versus shared decision-makers.

sion. Parents who preferred active participation in decisions regarding their presence at induction and on awakening had children who were significantly younger than parents who requested passive participation (induction, $5.6 \pm 4.8$ years versus $9.5 \pm 6.1$, $P<0.0001$ and awakening, $6.0 \pm 5.4$ versus $8.8 \pm 5.9$, $P=0.007)$.

Parents reported that they were extremely concerned about (in order by mode): the experience of the surgeon $(58.1 \%)$; the anaesthetist being nice to their child $(52.6 \%)$; the anaesthetist being present during the entire operation (50.6\%); their child experiencing pain $(49.7 \%)$; the experience of the

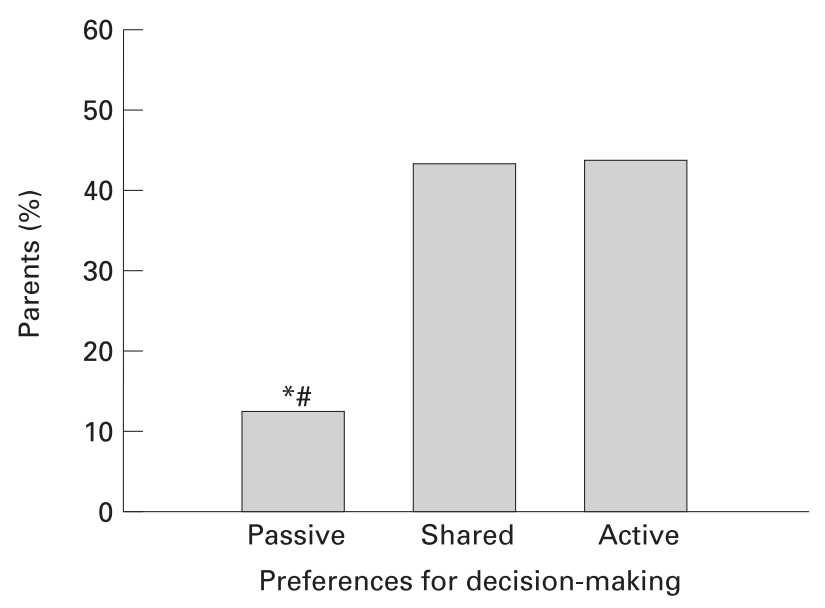

Figure 3

Parents' decision-making preferences with respect to their presence at induction. ${ }^{*} P<0.05$ versus active decision-makers, $\# P<0.05$ versus shared decision-makers.

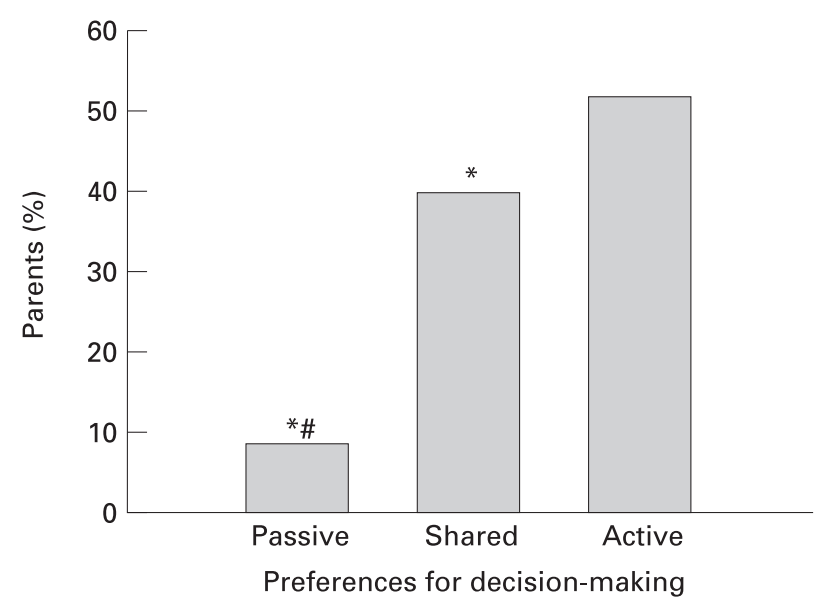

Figure 4

Parents' decision-making preferences with respect to their presence when their child wakes up. ${ }^{*} P<0.05$ versus active decisionmakers, $\# P<0.05$ versus shared decision-makers.

anaesthetist (47.4\%); and fear of the unknown $(40.9 \%)$. Overall parental anxiety was $6.9 \pm 2.7$ on the VAS indicating relatively high anxiety. There were no differences in parental anxiety levels by child's age, race, or previous surgery. Parents whose children were admitted postoperatively, however, were significantly more anxious than parents whose children were discharged home $(7.3 \pm 2.5$ versus $6.5 \pm 2.7, P=0.013)$. Also, parents whose education was beyond the high school graduate level were less anxious than those with a high school education only $(6.7 \pm 2.6$ versus $7.6 \pm 2.7, P=0.016$ ). 
Overall, parents were very satisfied with all aspects of their child's perioperative care. Analogue scores for satisfaction with anaesthetic care and surgical care, were $8.9 \pm 1.3$ and $9.3 \pm 1.2$, respectively. Comments regarding areas of dissatisfaction revealed that parents required more information regarding anaesthetic drugs and their side-effects, improved communication between the anaesthetist and themselves, and more input regarding decisionmaking. There were no differences between active, shared or passive decision-makers with respect to satisfaction with overall anaesthetic care $(8.8 \pm 1.2$ versus $8.9 \pm 1.4$ versus $9.0 \pm 1.1$, respectively, $P=\mathrm{NS})$ and participation in decision-making $(8.6 \pm 1.6$ versus $8.5 \pm 1.9$ versus $8.7 \pm 1.4$, respectively, $P=$ NS). Furthermore, there were no differences in satisfaction with respect to demographics. However, parents with education beyond the high school graduate level were significantly less satisfied than their less educated counterparts $(8.8 \pm 1.3$ versus $9.3 \pm 1.1, P=0.001)$. Parents of children who experienced PONV in the postanaesthesia care unit (PACU) were also less satisfied than parents whose children did not have PONV $(8.5 \pm 1.6$ versus $9.1 \pm 1.1, P=0.008$ ).

Overall, parents were satisfied with their participation in decision-making scoring $8.6 \pm 1.7$ by VAS. However, $99(32.1 \%)$ reported that they would have preferred greater participation in decision-making. Of these, $60(60.1 \%)$ stated that they would have liked more input with respect to pain control, 26 (26.3\%) for PONV management and 49 (49.5\%) for premedication. Parents who would have preferred more input into decision-making were significantly $(P<0.01)$ less satisfied than those who felt that their participation had been adequate (Table 2). Compared to passive decision-makers, parents who evidenced a preference for active participation in

Table 2

Parent satisfaction and perceived degree of participation (mean $\pm \mathrm{SD}$ )

\begin{tabular}{lll}
\hline Satisfaction with: & $\begin{array}{l}\text { More participation } \\
(\mathrm{n}=99)\end{array}$ & $\begin{array}{l}\text { Adequate participation } \\
(\mathrm{n}=190)\end{array}$ \\
\hline Anaesthetic care & $8.5 \pm 1.5^{*}$ & $9.2 \pm 1.1$ \\
Surgical care & $8.9 \pm 1.3^{*}$ & $9.4 \pm 1.1$ \\
Participation & $7.9 \pm 2.0^{*}$ & $9.0 \pm 1.3$ \\
\hline
\end{tabular}

${ }^{*} P<0.01$ versus adequate participation. decisions made regarding their child's need for premedication and their readiness for discharge were significantly more likely to have felt that their preferences had not been met (premed, $48.0 \%$ versus $26.8 \%, P=0.04$, discharge ready $45.5 \%$ versus $25.5 \%, P=0.04)$.

\section{Discussion}

Consumer dissatisfaction with the medical system and pressure from patient advocacy groups has led to a change in the traditional doctor-patient relationship. The once prominent paternalistic relationship in which the physician assumed the autonomous dominant role and the patient the passive dependent role has been challenged by a call for greater patient autonomy in making medical decisions (1). Although some authors have shown that actively involving patients in decision-making increases patient satisfaction, compliance with treatment regimens, knowledge (11), self-esteem and outcome $(2,3)$, others would argue that most patients are happy with the status quo and do not seek active participatory roles (4-6). Strull et al. showed that physicians substantially overestimate the amount of participation reported by patients in decision-making, underestimate the amount of information the patient desires, and in general, are poor judges of patient preferences for involvement in decisions regarding their care (4).

The hypothesis that active participation in decision-making improves parent satisfaction was rejected. This finding is likely due to the fact that overall satisfaction was uniformly high regardless of whether parents chose to be active, shared or passive decision-makers. It should be noted, however, that since there was were no differences in satisfaction scores between decision-making groups, the possibility of a type II error cannot be ruled out. This study did however, demonstrate that individual preferences for involvement in decision-making varied with respect to the different facets of their child's anaesthetic care. For example, the majority of parents were comfortable with the anaesthetist making decisions regarding intraoperative pain control but requested greater involvement in decisions regarding postoperative pain control. Barofsky (12) notes that not only does illness engender a feeling of loss of control in the 
patient, but the traditional process of medical care increases this loss. The apparent disparity in preferences for participation with respect to intraoperative and postoperative pain control may therefore reflect a parent's sense of 'loss of control' following separation from their child. Once separated, they relinquish decision-making control to the anaesthetist, and attempt to resume some sense of control when reunited with their child in the PACU. This theory may also explain parents' preferences for involvement in decisions regarding presence at induction and in the PACU when their child wakes up.

The issue of parental presence at induction has been a source of considerable debate for many years. Although some studies suggest that parental presence decreases anxiety (child's and parent's) and increases the child's cooperation $(13,14)$, Kain et al. showed no effect on several behavioural and physiological measures of anxiety (15). Vessey et al. showed that, parents are upset following separation from their child after induction, seeing their child go limp when anaesthetized, and seeing their child upset before induction (16). In a recent study by Kain et al. sedation with $0.5 \mathrm{mg} \cdot \mathrm{kg}^{-1}$ of oral midazolam together with parental presence at induction had no additive effects in reducing the child's anxiety but resulted in reduced parental anxiety and greater parental satisfaction (17). The degree of parental presence at induction appears to vary along international lines. For example, Kain et al. reported that in the USA, $58 \%$ of paediatric anaesthesiologists allow parental presence in less than $5 \%$ of cases. This contrasts significantly with the practice in the UK wherein parental presence at induction is relatively commonplace $(18,19)$. It should be noted that this study measured parents' preferences for decision-making regarding presence at induction rather than actual requests. However, the observation that parents preferred active participation in these decisions is in agreement with the findings of other studies (19-21).

The issue in which parents requested the greatest active involvement was that of parental presence when their child awakens in the PACU. Although this finding was somewhat surprising, it is nevertheless understandable given the high levels of parental anxiety and the desire of parents to be reunited with their children. Although practices with respect to parental presence on awakening vary by individual and institution, these results will be important to PACU nursing staff in educating parents and in establishing practice guidelines.

Although there are several studies that address satisfaction with various aspects of anaesthesia care (7-9), there are none, to our knowledge, that address satisfaction with paediatric anaesthesia care. Results of this study showed that parents' satisfaction with their child's anaesthetic care was generally high. However, parents who reported that they would have liked more participation were less satisfied with care suggesting that preferences are indeed an important component of satisfaction. Parents were most dissatisfied with what they perceived to be a lack of information with respect to the types of anaesthetic drugs and their side-effects. For example, some requested that the anaesthetist name the drugs to be given rather than being told that their child would have 'something to make them sleepy', or 'something to help with the pain.' This observation reflects the knowledge base of today's healthcare consumer and their desire for more complete information.

A potential limitation of this study is that it does not take into account individual parental coping styles since the manner in which parents cope with the stress of their child's surgery and their perceived degree of involvement in decision-making may have influenced their overall satisfaction. For example, parents who tend to use a passive coping style may be less satisfied if allowed active participation. Another consideration is that presenting this type of questionnaire to a parent may have initiated ideas for participation that otherwise may not have been considered. For example, parents may not always be aware of the options for control of nausea and vomiting and, as such, would not normally present a preference for decisions made regarding PONV management. Additionally, the timing of the questionnaire may have influenced some decisions.

Despite these potential limitations, it is clear that our patients are becoming increasingly knowledgeable regarding their options for care and, as such, will undoubtedly present increasing demands for greater decision-making involvement and autonomy. This study highlights those areas in which 
parents would ideally wish to be involved. From a practical standpoint, the perfunctory nature of the anaesthetist-parent/patient relationship does not typically allow sufficient time for education of the parents with respect to their options for all aspects of anaesthetic care. This study is important therefore, in identifying specific areas in which parents prefer a participatory role in decision-making and, as such, will allow anaesthetists to focus their attention and educational efforts towards those important areas. It is hoped that this approach will engender a greater sense of involvement and thus, satisfaction from parents.

It should be stressed that these authors do not necessarily advocate involving parents in all anaesthetic decisions. Obviously, most parents are illequipped to make decisions regarding the use of specific drugs for anaesthesia, pain control and PONV, and ultimately it is the anaesthetist's responsibility to apply the standards of care necessary to ensure the safety and welfare of their patient. However, parental involvement in the decisionmaking process does appear to be important and, as such, should be tailored to each parent, bearing in mind their level of knowledge and the constraints of individual hospital environments and practices. Parental and patient education, in concert with good communication, should therefore, be a priority. Brody (1) outlines four steps to encourage mutual clinical decision-making between physician and patient. These include: (i) establishing a conducive atmosphere and rapport; (ii) ascertaining the patients' goals and expectations; (iii) educating the patient regarding their options for care; and (iv) eliciting informed preferences.

Given the current emphasis on consumer satisfaction as a measure of health care quality and the growing trend towards greater patient/surrogate autonomy, these findings highlight the need for anaesthetists to be sensitive to parents' preferences for involvement in decisions made regarding their child's anaesthetic care.

\section{Acknowledgements}

The authors would like to thank Monica Siewert BA, Arti Desai, Jane Purakal, Agnieszka Trzcinka, Nisha Shajahan, Philip Rubin and Adam Tobias for help with patient recruitment and data collection. This paper was presented in part at the 6th Annual winter meeting of the Society for Pediatric Anesthesia, Ft Myers, Florida, February 2000. This study was supported in part by National Institutes of Health Grant RO1 GM61971.

\section{References}

1 Brody DS. The patient's role in clinical decision-making. Ann Intern Med 1980; 93: 718-722.

2 Greenfield S, Kaplan S, Ware JE. Expanding patient involvement in care: effects on outcome. Ann Intern Med 1985; 102: 520-528.

3 Brody DS, Miller SM, Lerman CE et al. Patient perception of involvement in medical care: relationship to illness attitudes and outcomes. J Gen Intern Med 1989; 4: 506-511.

4 Strull WM, Lo B, Charles G. Do patients want to participate in medical decision making? JAMA 1984; 252: 2990-2994.

5 Ende J, Kazis L, Ash A et al. Measuring patients' desire for autonomy: decision making and information seeking preferences among medical patients. J Gen Intern Med 1989; 4: 23-30.

6 Stiggelbout AM, Kiebert GM. A role for the sick role: patient preferences regarding information and participation in clinical decision-making. Can Med Assoc J 1997; 157: 383-389.

7 Dexter F, Aker J, Wright WA. Development of a measure of patient satisfaction with monitored anesthesia care: the Iowa Satisfaction with Anesthesia Scale. Anesthesiology 1997; 87: 865-873.

8 Whitty PM, Shaw IH, Goodwin DR. Patient satisfaction with general anaesthesia: too difficult to measure? Anaesthesia 1996; 51: 327-332.

9 Brown DL, Warner ME, Schroeder D et al. Effect on intraoperative anesthetic events on post-operative patient satisfaction. Mayo Clin Proc 1997; 72: 20-25.

10 Cella DF, Perry SW. Reliability and concurrent validity of three visual analogue mood scales. Psychol Rep 1986; 59: 827-833.

11 McKinley J. Who is really ignorant-physician or patient? J Health Soc Behav 1975; 16: 3-11.

12 Barofsky I. Compliance, adherence and the therapeutic alliance: steps in the development of self-care. Soc Sci Med 1978; 12: 369-376.

13 Kam PC, Voss TJ, Gold PD et al. Behaviour of children associated with parental participation during induction and general anesthesia. J Paediatr Child Health 1998; 34: 29-31.

14 Gillerman RG, Hinkle AJ, Green HM et al. Parental presence plus oral midazolam decreases frequency of $5 \%$ halothane induction in children. J Clin Anesth 1996; 8: 480-485.

15 Kain ZN, Mayes LC, Caramico LA et al. Parental presence during induction of anesthesia: a randomized controlled trial. Anesthesiology 1996; 84: 1060-1067.

16 Vessey JA, Bogetz MS, Caserza CL et al. Parental upset associated with participation in induction of anaesthesia in children. Can J Anaesth 1994; 41: 276-280.

17 Kain ZN, Mayes LC, Wang S-M et al. Parental presence and a sedative premedicant for children undergoing surgery: a hierarchical study. Anesthesiology 2000; 92: 939-946.

18 Kain ZN, Ferris CA, Mayes LC et al. Parental presence during induction of anaesthesia: practice differences between the United States and Great Britain. Paed Anaesth 1996; 6: 187-193. 
19 Ryder IG, Spargo PM. Parents in the anaesthetic room: a questionnaire survey of parents' reactions. Anaesthesia 1991; 46: 977-979.

20 Hichmott KC, Shaw EA, Goodyear I et al. Anaesthetic induction in children: the effects of maternal presence on mood and subsequent behaviour. Eur J Anaesthesiol 1989; 6: 145-155.
21 Braude N, Ridley SA, Sumner E. Parents and paediatric anaesthesia: a prospective survey of parental attitudes to their presence at induction. Ann R Coll Surg Engl 1990; 72: 41-44.

Accepted 22 August 2000 